\title{
Os dicionários Aurélio: análise das Expressões Idiomáticas sob o olhar da Lexicografia Pedagógica
}

\author{
Aurélio dictionaries: the \\ analysis of idioms under the \\ perspective of Pedagogical \\ Lexicography
}

Ariane Donizete Delgado Ribeiro CALDAS (UNESP) ariane.caldass@gmail.com

Odair Luiz NADIN da Silva (UNESP) odair.nadin@unesp.br Adriane ORENHA-OTTAIANO (UNESP) adriane.ottaiano@unesp.br

Recebido em: 31 de ago. de 2020. Aceito em: 22 de set. de 2020.

\section{0}

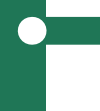

CALDAS, Ariane Donizete Delgado Ribeiro; NADIN, Odair Luiz da Silva; ORENHA-OTTAIANO, Adriane. Os dicionários Aurélio: análise das Expressões Idiomáticas sob o olhar da Lexicografia Pedagógica. Entrepalavras, Fortaleza, v. 11, n. esp., p. 163-179, ago. 2021. DOI: 10.22168/2237-6321-10esp2046.

Resumo: $O$ presente artigo visa empreender uma análise a partir de dois verbetes ( $p a ̃ o$ e ovo) em três dicionários da série Aurélio (Mini Aurélio, Aurélio Júnior e Aurélio), a fim de verificar a forma como as Expressões Idiomáticas são abordadas em cada dicionário. Os verbetes apresentados nesta pesquisa foram escolhidos por meio de uma análise quantitativa, que buscou evidenciar os dois verbetes mais frequentes a partir de uma lista de expressões idiomáticas compiladas por Seco (2017). A partir desta seleção e sob a ótica da Lexicografia Pedagógica, a qual nos diz que os dicionários destinados ao ensino de um idioma, seja ela materno ou estrangeiro, devem atender as necessidades dos alunos que os utilizarão, buscamos analisar como os dicionários selecionados abordam as Expressões Idiomáticas, com a finalidade de verificar como se dá a apresentação destas expressões aos alunos. Os dados analisados, embora parciais, demostraram que os dicionários deixam a desejar pedagogicamente, pois identificamos a falta de informações que são relevantes para os consulentes.

Palavras-chave: Lexicografia Pedagógica. Expressões Idiomáticas. Dicionários Aurélio. 
v. 11 (esp.)

163-179 ago.

2021

Abstract: This article aims to undertake an analysis based on two entries (bread and egg) in three dictionaries of the Aurélio line (Mini Aurélio, Aurélio Júnior and Aurélio), in order to verify how Idioms are addressed in each record. The entries presented in this research were selected through a quantitative analysis, which sought to highlight the two most frequent entries from a list of idioms compiled by Seco (2017). From this selection and from the perspective of Pedagogical Lexicography, that says to us that the type of dictionary designed to be used in the teaching of a language, whether mother or foreign, should attend to the needs of the students who use them, we seek to analyze how the selected dictionaries approach the Idioms, in order to check how these expressions are presented to students. This search concludes that, despite the delimitation of the clipping made here, the dictionaries the dictionaries fall short on the pedagogical aspect, as theywe identify the lack of information that is relevant to the consultants. We hope that this research could be deepened in the future, in order to prove the first data found.

Keywords: Pedagogical Lexicography. Idioms. Aurélio Dictionaries.

\section{Introdução}

A Lexicografia Pedagógica é uma área que vem ganhando destaque nas pesquisas no Brasil há pouco tempo, mais precisamente, desde o início dos anos 2000 (WELKER, 2011), fato que colabora com o surgimento de indagações e novos olhares sobre os dicionários reconhecidos nacional e internacionalmente que são utilizados no âmbito escolar, seja em aulas de língua materna, seja em aulas de língua estrangeira. Um dos exemplos deste crescimento e da importância da área é o número dedicado à Lexicografia Pedagógica da revista Domínios de Lingu@gem (v. 12, 2018), que conta com artigos de importantes estudiosos da área, como Krieger, Zavaglia, Bevilacqua e Nadin, entre tantos outros.

As pesquisas na área de Lexicografia Pedagógica, além de proporem o desenvolvimento de novos dicionários e glossários com fins pedagógicos, também privilegiam a análise e o estudo dos dicionários e glossários já existentes, de forma a promover discussões sobre os mais variados aspectos de cada dicionário, abrangendo questões que vão desde a hiperestrutura até a componentes da microestrutura de dicionários bilíngues e monolíngues.

Sendo assim, devido ao crescimento da área e tendo como motivação os artigos de Biderman (2000, 2002) nos quais a autora analisa dicionários de língua geral, o presente artigo surgiu com o intuito de analisar a forma como três dicionários de língua portuguesa, o AurélioJúnior, o MiniAurélio e o Aurélio, abordam as expressões idiomáticas em suas microestruturas, uma vez que estas unidades fraseológicas têm sido objeto de pesquisas que propõem o seu ensino aos alunos de língua materna (MATIAS; PARREIRA, 2011; CARVALHO, 2014; VACCARO TEER, 2018, entre outros). 
Embora estes dicionários não tenham sido contemplados pela distribuição do PNLD de 2012, foram escolhidos como objeto de análise devido ao destaque e renome que recebem por serem fruto do Dicionário Aurélio, desenvolvido por Aurélio Buarque de Holanda. Ademais, por serem produzidos por uma editora que alcança grande número de escolas de ensino fundamental e médio da rede particular de ensino, estes dicionários são consultados por alunos de todo o país.

A fim de delimitar os dados a serem analisados devido ao espaço deste artigo, partimos das expressões idiomáticas levantadas por Seco (2017) em seu trabalho sobre os gastronomismos presentes em expressões idiomáticas do português do Brasil e do francês da França e selecionamos os substantivos pão e ovo para exemplificar a análise feita, uma vez que são os mais frequentes no corpus composto pelas referidas expressões.

Dessa forma, este artigo parte dos pressupostos da Lexicografia Pedagógica, passando pelo suporte teórico relacionado ao ensino de Expressões Idiomáticas, além de contar com o auxílio de uma ferramenta da Linguística de Corpus, a saber, o programa WordSmith Tools, versão 7.0 (SCOTT, 2016), somente para a análise do corpus ${ }^{1}$ composto pelas expressões, tal como é explicitado na seção de metodologia de pesquisa. Após este item, apresentamos a análise comparativa entre os dados levantados nos três dicionários analisados para, depois, tecermos as considerações finais.

\section{Lexicografia pedagógica}

A Lexicografia Pedagógica, tal como o nome sugere, diz respeito aos dicionários que são utilizados no ensino-aprendizagem de línguas estrangeiras ou maternas. Mas, alguém pode questionar, os dicionários não são todos iguais? Por que, então, uma Lexicografia Pedagógica? Esperamos responder estas questões ao longo desta seção.

Embora a obra "O dicionário: estudo do vocabulário", de Sweet (1899), considerada como marco inicial de pesquisas sobre a Lexicografia Pedagógica seja do final do século XIX, autores como Molina García (2006) e Daré Vargas (2018), por exemplo, discorrem sobre o "giro de 180 graus"2 (MOLINA GARCÍA, 2006, p. 9) que aconteceu no ensino de

\footnotetext{
${ }^{1}$ Vale lembrar que, neste trabalho, a definição de corpus não está relacionada à perspectiva e aos preceitos da Linguística de Corpus, conforme será observado mais adiante.

2 "giro de 180 grados".
} 
v. 11 (esp.)

163-179 ago. 2021

línguas no início do século XX, a partir do qual passou-se a considerar a "adequação às necessidades do consulente-aprendente de LE" (DARÉ VARGAS, 2018, p. 1936). A partir de então, Harold Palmer, Michael West e A. S. Hornby (1930), passaram a ser considerados os responsáveis pelas pesquisas que marcaram o início da Lexicografia Pedagógica (doravante LP).

Mesmo não havendo um consenso entre os estudiosos da área sobre o marco inicial da LP, esta área, jovem ainda, vem ganhando destaque nas pesquisas lexicográficas (CASTILLO CARBALLO; GARCÍA PLATERO, 2003; FUENTES MORÁN, 1997, 2004, 2016; PRADO ARAGONÉS, 2005; DURAN; XATARA, 2007; CARVALHO; BAGNO, 2011; PONTES, 2010; NADIN, 2013, 2018; entre outros).

Uma vez que os dicionários pedagógicos passaram a ganhar destaque, retomamos aqui à primeira pergunta, respondendo que os dicionários não são todos iguais, já que possuem características diferentes, tendo os dicionários pedagógicos como principal característica o fato de levarem em conta as habilidades e as dificuldades, bem como as necessidades de consulta, que aprendizes de línguas apresentam (WELKER, 2011). Considerando a resposta à primeira pergunta, podemos dizer que a necessidade de se desenvolver pesquisas na área da LP está intimamente ligada às necessidades que os aprendizes de línguas estrangeiras ou materna, apresentam, ao consultarem os dicionários gerais de língua.

Para Welker (2011, p. 109), ao se elaborar um dicionário pedagógico, deve-se considerar "as reais necessidades e as habilidades dos usuários, o que significa que devem ser produzidos dicionários diferentes para aprendizes com níveis diferentes de competência linguística". Segundo o autor, este é o princípio fundamental da LP, o que nos leva a entender a necessidade de desenvolvimento de pesquisas na área, bem como sua importância.

De acordo com Welker (2008, p. 15), normalmente, ao empregarem o termo LP, os autores fazem referência aos learners' dictionaries (dicionários para aprendizes de línguas estrangeiras), como em Hartmann (1995), Kernemann (2000), Meer (2005), Wiegand (1998a, 2002a), para citar alguns. Quanto às pesquisas em âmbito nacional, segundo Welker (idem), Duran (2004) e Duran e Xatará (2006) abordam apenas dicionários de francês como língua estrangeira. Contudo, os dicionários de língua materna também são contemplados pelas pesquisas em LP. Atualmente, temos os trabalhos de Damin (2005), 
Matias e Parreira (2011), Rodrigues (2015), Santiago (2012, 2015), que são apenas alguns dentre os trabalhos desenvolvidos na área de LP e língua materna.

De modo geral, tanto os dicionários pedagógicos bilíngues quanto os dicionários de língua materna "auxiliam na alfabetização e no desenvolvimento da competência de leitura. Podem ainda auxiliar muito nos estudos descritivos da língua, tornando-se obras essenciais a toda aprendizagem de língua materna e também de outras disciplinas curriculares" (KRIEGER; WELKER, 2011, p. 109-110).

\section{As Expressões Idiomáticas}

As Expressões Idiomáticas (doravante EIs) constituem um dos vários tipos de unidades fraseológicas que são estudadas pela Fraseologia e, como tal, possuem definições variadas, desde a mais simples, até definições mais elaboradas. Neste trabalho, entendemos que uma expressão idiomática é "uma lexia complexa indecomponível, conotativa e cristalizada em um idioma pela tradição cultural" (XATARA, 1994, 1998).

Além disso, as EIs são comumente conhecidas como sendo unidades típicas da fala, da linguagem coloquial, tal como afirma Seco (2017, p. 25), fato associado à sua cristalização em dado idioma por meio da tradição cultural, e que corrobora para que estas unidades fraseológicas não tenham recebido muito destaque em pesquisas que privilegiam o seu ensino-aprendizagem, principalmente em língua materna, devido à crença de que

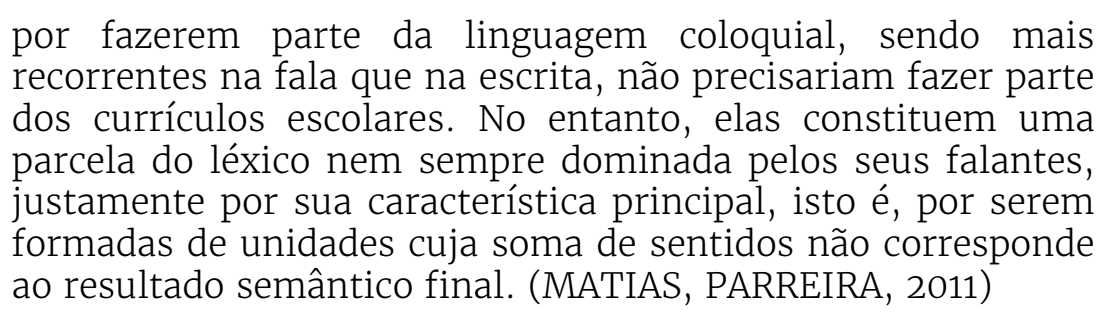

Tal como advoga Carvalho (2014, p. 169), "devido ao seu caráter cultural, estas expressões devem figurar em materiais de apoio ao processo de ensino/aprendizagem com o objetivo de formar falantes competentes que conheçam o 'colorido do povo' que utiliza a língua em questão", e esta afirmação deve ser aplicada, também, ao ensino de língua materna, uma vez que as EIs, de acordo com o exposto, tendem a surgir na oralidade e na linguagem coloquial, porém perpassam 
v. 11 (esp.)

163-179 ago. 2021

o falar do povo de um país, o que faz com que os alunos tenham dificuldades em decodificar o sentido metafórico em cada EI, devido à sua composicionalidade.

Dessa forma, podemos dizer que as EIS são

idiossincrasias que individualizam uma dada comunidade, são, pois, particularidades que caracterizam um povo e representam a cultura partilhada por ele. Elas foram criadas no decorrer do tempo a partir das vivências e experiências de um povo, sendo metáforas do que se passou (CARVALHO, 2014, p. 169).

Uma vez que as EIs são responsáveis por caracterizar um povo e representar o que compartilham, nada mais justo do que se tornarem parte do léxico que deve ser ensinado nas escolas, dada sua riqueza cultural e histórica.

As pesquisas atuais que abordam o tema das EIs com um viés pedagógico, tais como a de Matias e Parreira (2011) e a de Carvalho (2014), o fazem a partir do ponto de vista da Lexicografia Pedagógica, ou seja, consideram o ensino-aprendizagem das expressões tendo como ponto de partida as expressões que são encontradas em dicionários, sejam estes gerais ou especiais ${ }^{3}$. Dessa forma, espera-se que os dicionários direcionados para o público-alvo deste trabalho, a saber, alunos dos ensinos fundamental e médio, tragam exemplos de EIs, bem como definições claras e de fácil compreensão para eles.

Convém ressaltar que não se espera que um dicionário de língua geral produzido para o público em questão contenha todas as informações relacionadas a cada uma das EIs existentes em nosso idioma. Contudo, espera-se que as EIs mais frequentes e, consequentemente, mais comuns, sejam contempladas pelos dicionários.

\section{Metodologia de Pesquisa}

Para o desenvolvimento desta pesquisa, tomamos como ponto de partida as expressões idiomáticas apresentadas no trabalho desenvolvido por Seco (2017), as quais estão relacionadas aos gastronomismos. Neste trabalho, a autora analisa os gastronomismos que compõem expressões idiomáticas da língua portuguesa e da língua francesa, buscando identificar a carga cultural partilhada em ambos os

\footnotetext{
${ }^{3}$ Aqui, entendemos por dicionários gerais aqueles que se caracterizam por serem "alfabéticos, síncronos, da língua contemporânea, arrolando sobretudo os lexemas da língua comum". Enquanto os dicionários especiais são "os históricos, os diacrônicos, os onomasiológicos, etc." (WELKER, 2004, p, 43)
} 
idiomas. No que diz respeito à coleta das EIs que foram analisadas, a autora explica que houve três tipos de coleta: a primeira, que contou com três dicionários especiais que tratam das EIs, além de contar com um material lexicográfico paradidático; a segunda, na qual foram utilizados informantes para a coleta das EIs; e por último, a terceira fase, na qual foram confirmadas as informações obtidas na segunda fase por meio da verificação em dois dicionários gerais de língua portuguesa (SECO, 2017, p. 73).

Uma vez que a coleta das EIs apresentadas no referido trabalho se deu de forma abrangente e diversificada, tendo sido encontradas em dois dicionários gerais de língua portuguesa, optamos por observar a forma como as EIs são abordadas em dicionários direcionados especificamente aos estudantes brasileiros.

Sendoassim, buscamosanalisarapresençads EIs nos dicionários Aurélio Júnior, $2^{\mathrm{a}}$ edição, de 2011, e Mini Aurélio, $8^{\mathrm{a}}$ edição, também de 2011, os quais são indicados para alunos do Ensino Fundamental II e Ensino Médio, respectivamente, além do próprio dicionário Aurélio, $4^{\mathrm{a}}$ edição, de 2004. A escolha destes dicionários se deve ao fato do destaque e renome alcançados pelo dicionário produzido por Aurélio Buarque de Holanda, bem como por estes serem produzidos, atualmente, por uma editora escolar que abrange um número expressivo de alunos do ensino Fundamental II e Médio.

Dessa forma, nesta pesquisa, coletamos as EIs em língua portuguesa apresentadas no trabalho de Seco (2017) e fizemos uma análise quantitativa por meio da ferramenta WordList do programa WordSmith Tools, versão 7.0 (SCOTT, 2016), a fim de delimitarmos os substantivos mais frequentes, de modo que estes se configurassem em nosso ponto de partida para a busca das EIs, uma vez que os substantivos aparecem em mais de uma expressão, em sua maioria. Convém ressaltar que o corpus compilado conta com um total de 111 EIs. A seguir, apresentamos uma imagem com as primeiras 35 palavras mais frequentes em nosso corpus composto pelas EIs, com destaque para as duas palavras de conteúdo que foram escolhidas como objeto de análise: 


\section{v. 11 (esp.)}

163-179 ago.

2021
Imagem 1 - Resultados obtidos pela ferramenta WordList

W F:\Doutorado\Disciplina Lexicografia Pedagógica\Artigo final\Corpus Els Gastronomismos.Ist File Edit View Compute Settings Windows Help

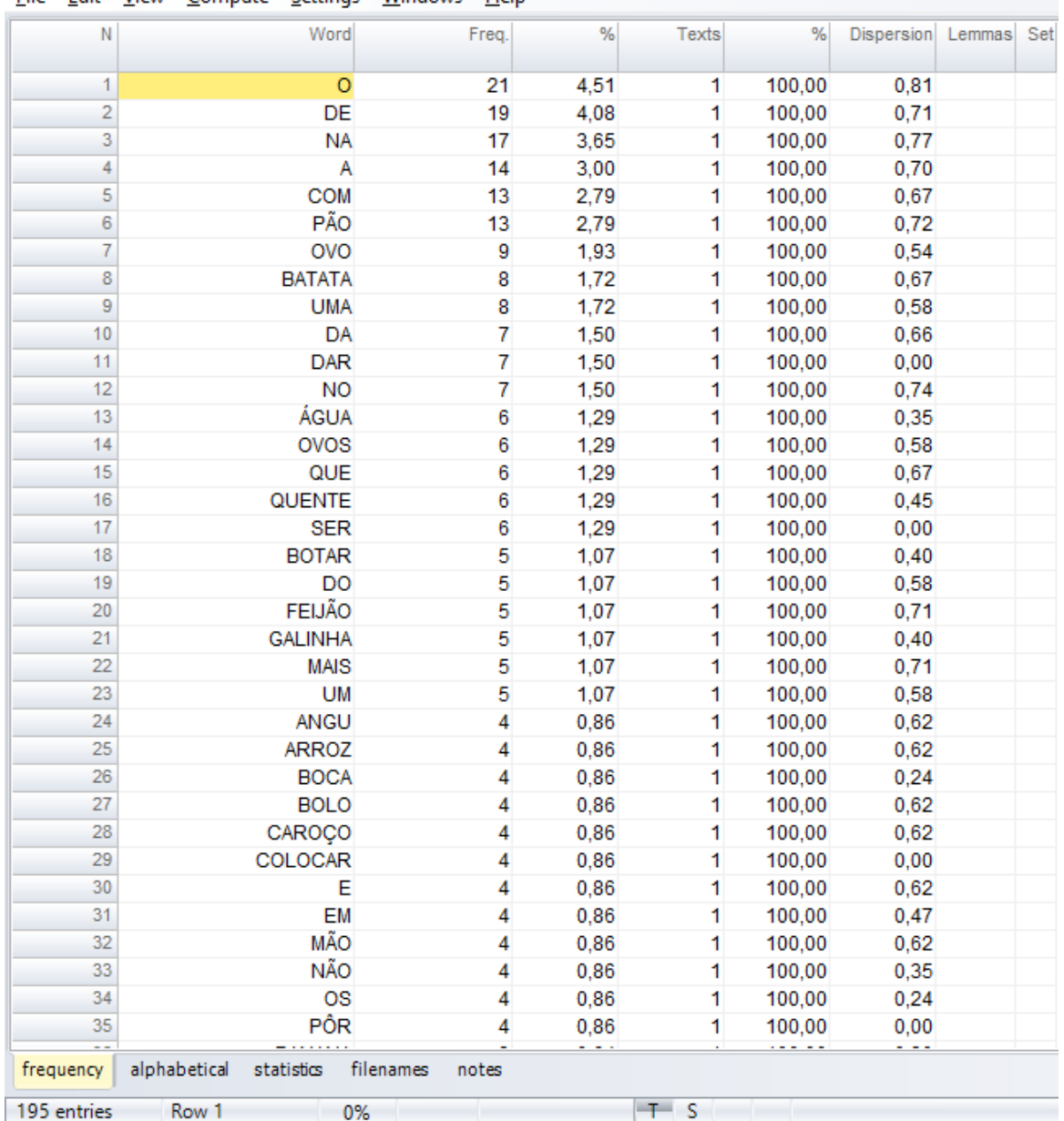

Fonte: Próprio da pesquisa.

As palavras pão e ovo foram escolhidas por serem os substantivos mais frequentes em nosso corpus e, dessa forma, a busca pelas EIs nos dicionários mencionados, a saber, Aurélio Júnior e Mini Aurélio, será feita por meio dos verbetes referentes a estas duas palavras. Esta opção de busca por apenas dois verbetes em ambos os dicionários se faz necessário devido à delimitação dada a este artigo.

Ademais, uma vez que o próprio dicionário Aurélio não foi um dos dicionários consultados para a compilação das EIs no trabalho de Seco (2017), também buscamos as entradas referentes a pão e ovo neste dicionário, a fim de verificarmos a presença ou ausência das EIs que compõem o corpus coletado pela autora.

As informações relacionadas à análise destes verbetes, bem como as EIs encontradas, são apresentadas na seção a seguir. 


\section{Análise dos verbetes}

Conforme mencionamos na seção anterior, selecionamos os dois substantivos mais frequentes no corpus composto pelas EIs com gastronomismos, a saber, pão e ovo, a fim de que estas palavras se tornassem os verbetes analisados em ambos os dicionários (Aurélio Júnior e Mini Aurélio), de forma a evidenciar a forma como as EIs são apresentadas, bem como sua presença ou não.

Sendo assim, apresentamos na tabela a seguir os dados encontrados em ambos os verbetes no dicionário Aurélio Júnior.

Tabela 1 - Presença e ausência de EIs no dicionário Aurélio Júnior

\begin{tabular}{|c|c|l|}
\hline VERBETE & PRESENÇA OU AUSÊNCIA DE EIS & \multicolumn{1}{|c|}{ EXEMPLOS } \\
\hline PÃO & Ausência & \\
\hline OVO & Presença & $\begin{array}{l}\text { Pisar em ovos } \\
\text { Ser um ovo }\end{array}$ \\
\hline
\end{tabular}

Fonte: Próprio da pesquisa.

Como se pode perceber, o dicionário Aurélio Júnior não traz nenhum exemplo de expressão idiomática para o verbete pão. Entretanto, apresenta uma entrada com o verbete pão-duro, o qual é definido como um brasileirismo. Já em relação ao verbete ovo, temos dois exemplos de EIs, pisar em ovos e ser um ovo, as quais são respectivamente definidas como conduzir-se com cautela ou habilidade por se tratar de situação delicada ou embaraçosa e ser (um lugar) muito pequeno.

Quanto ao dicionário Mini Aurélio, foi possível levantar os seguintes dados, apresentados na tabela abaixo:

Tabela 2 - Presença e ausência de EIs no dicionário Mini Aurélio.

\begin{tabular}{|c|c|l|}
\hline VERBETE & $\begin{array}{c}\text { PRESENÇA OU } \\
\text { AUSENCIA DE EIs }\end{array}$ & EXEMPLOS \\
\hline PÃO & Ausência * & $\begin{array}{l}\text {. Pão árabe*; } \\
\text { Pão de forma*; } \\
\text { - Pão francês*; } \\
\text { Pão integral*; }\end{array}$ \\
\hline OVO & Presença & Pisar em ovos \\
\hline
\end{tabular}

Fonte: Próprio da pesquisa.

Ao analisarmos a tabela, percebemos que o Mini Aurélio apresenta um asterisco ao lado da informação ausência para o verbete 
v. 11 (esp.)

163-179 ago. 2021

pão, bem como ao lado dos exemplos encontrados neste verbete, o que se explica pelo fato de não ter sido encontrada nenhuma expressão idiomática relacionada a este verbete, mas sim, alguns exemplos de locuções. Já no verbete ovo, podemos identificar a expressão pisar em ovos, a qual apresenta a seguinte definição "conduzir-se com cautela ou habilidade, por estar em situação delicada".

Com relação a este dicionário, convém ressaltar que, nas páginas em que explica os seus símbolos, apresenta a informação de que o símbolo $\diamond$ é utilizado para introduzir as locuções formadas pela palavra entrada do verbete, não fazendo nenhuma menção a expressões idiomáticas. Contudo, podemos perceber que há uma confusão por parte do dicionário, uma vez que considera como locução inclusive as EIs, tal como pisar em ovos, além das locuções apresentadas no verbete pão4.

Ainda sobre a questão do símbolo utilizado para introduzir as locuções no Mini Aurélio, podemos dizer que o mesmo símbolo é utilizado no Aurélio Júnior, porém, neste dicionário, é responsável por indicar locuções ou expressões idiomáticas.

A título de comparação, trazemos a análise dos verbetes pão e ovo como são apresentados no dicionário Aurélio (2004). Ressaltamos que, no quadro a seguir, foram descartadas as locuções que também são apresentadas junto às EIs após o símbolo $\diamond$.

Tabela 3 - Presença e ausência de EIs no dicionário Aurélio (continua)

\begin{tabular}{|c|c|c|}
\hline VERBETE & $\begin{array}{c}\text { PRESENCCA / } \\
\text { AUSÊNCIA DE EIs }\end{array}$ & EXEMPLOS \\
\hline PÃO & Presença & $\begin{array}{ll}\cdot & \text { Pão, pão, queijo, queijo } \\
\cdot & \text { A pão e água } \\
& \text { A pão e laranja } \\
& \text { Comemor o pãa que o diabo } \\
& \text { amassou } \\
\cdot & \text { Comer pão com banha } \\
\cdot & \text { Fazer pão grande } \\
& \text { O pão nosso de cada dia } \\
& \text { Rente como pão quente } \\
& \text { Tirar o pão da boca de }\end{array}$ \\
\hline
\end{tabular}

4 Por conta da delimitação do espaço deste artigo, não discutiremos os exemplos apresentados aqui como locuções, as quais constituem-se em locuções gramaticais, tais como as adverbiais, prepositivas e conjuncionais, uma vez que estas são apresentadas como subentradas dos verbetes em análise e não constituem expressões idiomáticas por si só. (BIDERMAN, 2002, p. 88). 
Tabela 3 - Presença e ausência de EIs no dicionário Aurélio (conclusão)

\begin{tabular}{|c|c|c|}
\hline VERBETE & $\begin{array}{c}\text { PRESENCCA / } \\
\text { AUSÊNCIA DE EIs }\end{array}$ & EXEMPLOS \\
\hline OVO & Presença & $\begin{array}{ll}\cdot & \text { Ovo de Colombo } \\
\cdot & \text { Balançar o ovo de } \\
\cdot & \text { Cheio como um ovo } \\
\cdot & \text { Cheio que nem ovo } \\
\cdot & \text { Chupar o ovo de } \\
\cdot & \text { Contar com o ovo na } \\
\text { · } & \text { Conda da galinha } \\
& \text { da galinha o ovo no cu } \\
\cdot & \text { De ovo virado } \\
\cdot & \text { De pocar o ovo } \\
\cdot & \text { Fazer ovo } \\
\cdot & \text { No ovo } \\
\cdot & \text { Pisar em ovos } \\
\cdot & \text { Ser um ovo } \\
& \text { Um ovo por um real }\end{array}$ \\
\hline
\end{tabular}

Fonte: Próprio da pesquisa.

Tal como pode ser observado no quadro anterior, a quantidade de EIs nos verbetes pão e ovo presentes no Dicionário Aurélio é muito maior que a encontrada nos dicionários Aurélio Júnior e Mini Aurélio. Este fato pode estar relacionado ao tamanho e, consequentemente, ao espaço que o Dicionário Aurélio tem quando comparado aos outros dois, o que permite que seja apresentada uma quantidade muito maior de informações sobre cada verbete do dicionário.

Contudo, o que nos chama a atenção, após termos os dados referentes aos três dicionários analisados, é a ausência de expressões idiomáticas para o verbete pão nos dois dicionários menores, uma vez que são apresentadas 10 expressões com a presença deste substantivo no dicionário Aurélio. De forma semelhante, temos 11 expressões listadas no verbete ovo, no referido dicionário, enquanto o dicionário Aurélio Júnior apresenta apenas duas e o Mini Aurélio apenas uma.

No quadro a seguir, apresentamos as EIs encontradas nos três dicionários analisados, bem como as informações gramaticais dadas sobre cada uma e suas respectivas definições: 
v. 11 (esp.)

163-179

ago.

2021

Tabela 4 - Expressões idiomáticas encontradas nos três dicionários (continua)

\begin{tabular}{|c|c|c|c|}
\hline Expressão Idiomática & Dicionário & Marcas de Uso & Definição \\
\hline Pão, pão, queijo, queijo & Aurélio & Fam. & $\begin{array}{l}\text { Sem rodeios ou } \\
\text { subterfúgios; às claras; } \\
\text { claramente }\end{array}$ \\
\hline A pão e água & Aurélio & & À mingua \\
\hline A pão e laranja & Aurélio & & $\begin{array}{l}\text { Quase na miséria, ou na } \\
\text { miséria }\end{array}$ \\
\hline Bom como pão & Aurélio & & $\begin{array}{l}\text { 1. Muito bom, generoso } \\
\text { e simples. } 2 \text {. Bom como } \\
\text { água. }\end{array}$ \\
\hline $\begin{array}{l}\text { Comer o pão que o } \\
\text { diabo amassou }\end{array}$ & Aurélio & $\begin{array}{l}\text { V. comer da } \\
\text { banda podre.* }\end{array}$ & \\
\hline Comer pão com banha & Aurélio & Bras. Chulo & $\begin{array}{l}\text { Possuir mulher que acaba } \\
\text { de ser possuída por outro. }\end{array}$ \\
\hline Fazer pão grande & Aurélio & Bras. Pop. & $\begin{array}{l}\text { Viver na indolência, na } \\
\text { ociosidade. }\end{array}$ \\
\hline $\begin{array}{l}\text { O pão nosso de cada } \\
\text { dia }\end{array}$ & Aurélio & Fig. & $\begin{array}{l}\text { O que se faz ou acontece } \\
\text { cotidianamente. }\end{array}$ \\
\hline Rente como pão quente & Aurélio & Bras. Fam. & $\begin{array}{l}\text { Com toda a assiduidade ou } \\
\text { pontualidade. }\end{array}$ \\
\hline Tirar o pão da boca de & Aurélio & & $\begin{array}{l}\text { Privar dos meios de } \\
\text { subsistência. }\end{array}$ \\
\hline Ovo de Colombo & Aurélio & & $\begin{array}{l}\text { Coisa fácil de realizar, mas } \\
\text { na qual não se pensou } \\
\text { antes de a ver posta em } \\
\text { prática. }\end{array}$ \\
\hline Balançar o ovo de & Aurélio & $\begin{array}{l}\text { Bras. Al. Chulo } \\
\text { V. }\end{array}$ & Bajular \\
\hline Cheio como um ovo & Aurélio & & Cheio que nem ovo \\
\hline Cheio que nem ovo & Aurélio & & $\begin{array}{l}\text { 1. Muito rico. 2. Muito } \\
\text { cheio, repleto. }\end{array}$ \\
\hline Chupar o ovo de & Aurélio & $\begin{array}{l}\text { Bras. Al. Chulo } \\
\text { V. }\end{array}$ & Bajular \\
\hline $\begin{array}{l}\text { Contar com o ovo na } \\
\text { bunda da galinha }\end{array}$ & Aurélio & Bras. Chulo & $\begin{array}{l}\text { Fazer planos com base em } \\
\text { coisa incerta; contar com o } \\
\text { ovo no cu da galinha. }\end{array}$ \\
\hline $\begin{array}{l}\text { Contar com o ovo no } \\
\text { cu da galinha }\end{array}$ & Aurélio & Bras. Chulo & $\begin{array}{l}\text { Contar com o ovo na bunda } \\
\text { da galinha. }\end{array}$ \\
\hline De ovo virado & Aurélio & Bras. Pop. & De mau humor \\
\hline De pocar o ovo & Aurélio & $\begin{array}{l}\text { Bras. N. E. } \\
\quad \text { Chulo }\end{array}$ & $\begin{array}{l}\text { 1. Extraordinário, } \\
\text { admirável; do outro } \\
\text { mundo. 2. Dos diabos; de } \\
\text { todos os diabos. }\end{array}$ \\
\hline
\end{tabular}


Tabela 4 - Expressões idiomáticas encontradas nos três dicionários (conclusão)

\begin{tabular}{|c|c|c|c|}
\hline Expressão Idiomática & Dicionário & Marcas de Uso & Definição \\
\hline Fazer ovo & Aurélio & & $\begin{array}{l}\text { Fazer mistério em torno de } \\
\text { algum fato. }\end{array}$ \\
\hline No ovo & Aurélio & Bras. Fig. & $\begin{array}{l}\text { Em embrião; no germe, no } \\
\text { princípio, na origem, no } \\
\text { começo, no início }\end{array}$ \\
\hline Pisar em ovos & $\begin{array}{l}\text { Aurélio / } \\
\text { Mini } \\
\text { Aurélio / } \\
\text { Aurélio } \\
\text { Júnior }\end{array}$ & & $\begin{array}{l}\text { Conduzir-se com } \\
\text { cautela, diplomacia, } \\
\text { habilidade, por tratar-se } \\
\text { de situação delicada e/ou } \\
\text { constrangedora. (Aurélio) } \\
\text { Conduzir-se com cautela } \\
\text { ou habilidade, por estar } \\
\text { em situação delicada. (Mini } \\
\text { Aurélio) } \\
\text { Conduzir-se com cautela } \\
\text { ou habilidade por tratar- } \\
\text { se de situação delicada ou } \\
\text { embaraçosa (Aurélio Júnior). }\end{array}$ \\
\hline Ser um ovo & $\begin{array}{l}\text { Aurélio / } \\
\text { Aurélio } \\
\text { Júnior }\end{array}$ & & $\begin{array}{l}\text { Ser muito pequeno, ou } \\
\text { muito estreito, ou pouco } \\
\text { cômodo. (Aurélio) } \\
\text { Ser (um lugar) muito } \\
\text { pequeno. (Aurélio Júnior) }\end{array}$ \\
\hline Um ovo por um real & Aurélio & & Coisa muitíssimo barata \\
\hline
\end{tabular}

Como podemos perceber pelos dados apresentados no quadro acima, apenas 12 EIs trazem algum tipo de marcas de uso e uma traz uma remissiva sem que haja alguma marca de uso ou uma definição (comer o pão que o diabo amassou, sinalizada com um asterisco ao lado da remissiva).

Com relação às definições dadas às EIs, apenas a expressão comer o pão que o diabo amassou não possui definição, fato que está relacionado à presença de uma remissiva indicando outra entrada na qual há uma definição.

Ao todo, foram encontradas 24 EIs a partir das buscas realizadas nos verbetes pão e ovo dos três dicionários analisados, sendo que deste total, apenas uma foi encontrada em todos os dicionários analisados, a saber, pisar em ovos. Esse resultado, embora tenha sido obtido por meio de um recorte bem pequeno, nos chama a atenção para a ausência de EIs nos dicionários destinados ao público em idade escolar, fase em que estão desenvolvendo seus conhecimentos acerca da riqueza lexical da língua materna, o que os leva a perder contato com uma parte importante da nossa cultura, tal como ressalta Carvalho (2014). 
v. 11 (esp.)

163-179 ago.

2021

\section{Considerações Finais}

Neste artigo, buscamos apresentar uma análise das EIs em três dicionários da série Aurélio, produzidos pela mesma editora, sob a ótica da Lexicografia Pedagógica, a qual nos diz que os dicionários direcionados ao ensino-aprendizagem de um idioma, seja ele estrangeiro ou materno, deve atender às necessidades do usuário, sendo de fácil compreensão, acesso e manuseio.

Como podemos perceber por meio dos dados apresentados, os dicionários AurélioJúnior e MiniAurélio, ambos destinados a alunos do Ensino Fundamental II e Ensino Médio, respectivamente, podem não apresentar as EIs de forma mais abrangente, levando ao possível comprometimento do aprendizado de um aspecto cultural de nossa língua muito importante para um aprendiz nas idades enfocadas. Em nenhum dos dois dicionários foi encontrada alguma EI relacionada ao verbete pão, verbete este que traz entre suas subentradas um total de 10 EIs no dicionário Aurélio.

Em contrapartida, o verbete ovo traz duas EIs no dicionário Aurélio Júnior e uma no Mini Aurélio. Contudo, em nenhum dos dicionários existe a presença de marcas de uso, recurso que indica ao aluno (consulente) em que contexto ou contextos a expressão em questão é normalmente utilizada.

Ressaltamos, que, a presente pesquisa buscou analisar apenas dois verbetes devido a questões de delimitação de tempo e espaço, sendo essa uma das suas limitações. Ademais, não houve tempo hábil para que pudéssemos ampliar a análise de tais verbetes para os dicionários contemplados pelo PNLD.

Outrossim, esta amostra aqui apresentada, bem como os resultados obtidos, nos permite contribuir com a área da Lexicografia Pedagógica, além de instigar a questionar a forma como as EIs são abordadas pelos dicionários de língua materna, principalmente os dicionários direcionados aos alunos de Ensino Fundamental il e Ensino Médio, de forma que, espera-se que estes questionamentos sirvam de incentivo para que novas e maiores pesquisas na área sejam empreendidas, a partir do que discutimos aqui.

\section{Referências}

BIDERMAN, M. T. Análise dos dicionários gerais do português brasileiro contemporâneo: o Aurélio e o Houaiss. Filologia e Linguística Portuguesa. n. 5, 2002. p. $85-116$. 
BIDERMAN, M. T. Aurélio: sinônimo de dicionário? Alfa, São Paulo. n.44. 2000. p. $27-55$.

CARVALHO, G. L. "Dar uma colher de chá": uma análise de expressões idiomáticas em dicionários de língua portuguesa. Revista Domínios da Lingu@gem.v. 8, n. 2. 2014. p.164-177.

CARVALHO, O. L. de S.; BAGNO, M. (orgs.). Dicionários Escolares: políticas, formas e usos. São Paulo: Parábola, 2011.

CASTILLO CARBALLO; M. A.; GARCÍA PLATERO, J. M. La lexicografía didáctica. En: MEDINA GUERRA, A. M. (coord.). Lexicografía Española. Barcelona: Ariel, 2003.

DAMIN, C. P. Parâmetros para uma avaliação do dicionário escolar. 2005. 230 f. Dissertação (Mestrado em Letras). Universidade Federal do Rio Grande do Sul. Instituto de Letras, Programa de Pós-Graduação em Letras. Porto Alegre, 2005.

DARÉ VARGAS, M. Lexicografia pedagógica: história e panorama em contexto brasileiro. Revista Domínios da Lingu@agem. Uberlândia. v. 12, n. 4. 2018, p. $1934-1949$.

DURAN, M. S. Dicionário bilíngues pedagógicos: análise, reflexões e propostas. 2004. 132 f. Dissertação (Mestrado em Estudos Linguísticos). Instituto de Biociências, Letras e Ciências Exatas, Universidade Estadual Paulista, São José do Rio Preto. 2004.

DURAN, M. S.; XATARA, C. M. Lexicografia Pedagógica: atores e interfaces. D.E.L.T.A. 23:2, 2007, p. 203-222.

FERREIRA, A. B. H. Aurélio Júnior: dicionário escolar da língua portuguesa. 2. ed. Curtiba: Positivo. 2011.

FERREIRA, A. B. H. Mini Aurélio: o dicionário da língua portuguesa. 8. ed. Curitiba: Positivo, 2010.

FERREIRA, A. B. H. Novo dicionário Aurélio da língua portuguesa. 3. ed. Curitiba: Positivo, 2004.

FUENTES MORÁN, M. T. Entrar en el diccionario. Apuntes sobre la selección de entradas. P. FABER; C. JIMÉNEZ Y G. WOTJAK (eds.). Léxico especializado y comunicación interlingüística. Granada: Granada Lingüística, 2004, p. 5972.

FUENTES MORÁN, M. T. Gramática en la lexicografía bilingüe. Morfología y sintaxis en diccionarios español-alemán desde el punto de vista del germanohablante. Tübingen: Niemeyer (Lexicographica, Series Mayor 81), 1997.

FUENTES MORÁN, M. T.; NADIN, O. L. Algunas formas de presentación de datos en diccionarios de español para aprendices brasileños. In. NADIN, O. L.; ZAVAGLIA, C. Estudos do Léxico em Contextos Bilíngues. Campinas: Mercado de Letras, 2016, p. 53-78. 
v. 11 (esp.)

163-179 ago.

2021

KRIEGER, M. G.; WELKER, H. A. Questões de Lexicografia Pedagógica. In: XATARA; BEVILACQUA; HUMBLÉ (orgs). Dicionários na teoria e na prática: como e para quem são feitos. São Paulo: Parábola Editorial, 2011.

MATIAS, G. L.; PARRERIA, M. C. O ensino de expressões idiomáticas à luz da Lexicografia Pedagógica. Pesquisas em discursos pedagógicos. v.2. 2011.

MOLINA GARCÍA, D. Fraseología bilíngue: un enfoque lexicográficopedagógico. Granada: Comares, 2006.

NADIN, O. L. O uso do dicionário nas aulas de espanhol como língua estrangeira: reflexões teórico-práticas. In: Odair Luiz Nadin e Viviane Cristina Poletto Lugli. (Org.). Espanhol como Língua Estrangeira: reflexões teóricas e propostas didáticas. Campinas: Mercado de Letras, 2013, v. 1, p. 139-150

PONTES, A. L. Exemplo lexicográfico em dicionários escolares brasileiros. Filologia linguística portuguesa. N. 12(2), p. 351-370, 2010.

PRADO ARAGONÉS, J. El uso del diccionario para la enseñanza de la lengua: consideraciones metodológicas. En: Káñina, Rev. Artes y Letras, Univ. Costa Rica. Vol. XXIX (Especial), 2005, pp. 19-28.

RODRIGUES, L. T. D. Dicionários distribuídos pelo PNLD: análise da microestrutura de quatro dicionários de língua portuguesa. Revista Primeira Escrita, Aquidauana, n. 2, 2015. p. 78-93.

SANTIAGO, M. S. Análises contrastivas de microestruturas em dicionários escolares. Pesquisas em discursos pedagógicos. V.1. 2012.

SANTIAGO, M. S. Critérios de avaliação de dicionários escolares de língua portuguesa no Programa Nacional do Livro Didático. In: ARAUJO.; PEREIRALIMA; DUARTE (et al). Reflexões Linguísticas e Literárias. Fortaleza - CE: HBM Shoping das Cópias. 2015.

SECO, M. Gastronomismos nas Expressões Idiomáticas do português do Brasil e seus correspondentes em francês da França. 2017. 188f. Dissertação (Mestrado em Estudos Linguísticos) - Instituto de Biociências, Letras e Ciências Exatas, Universidade Estadual Paulista, São José do Rio Preto. 2017.

SCOTT, M. WordSmith Tools. Versão 7.0. Liverpool: Lexical Analysis Software, 2016.

SWEET, H. The Practical Study of Language. Oxford University Press, London. 1899.

VACCARO TEER, J. A lematização de expressões idiomáticas em dicionários para aprendizes. In: ZAVAGLIA, C.; NADIN, O. L. (orgs). Lexicografia Pedagógica. Revista Domínios de Lingu@gem. Uberlândia, Universidade Federal de Uberlândia, v. 12, n. 4. 2018, p. 2363 - 2383.

XATARA, C. M. Tipologia das expressões idiomáticas. ALFA: Revista de Linguística, v. 42, n. 1, p. 169-176, 1998.

XATARA, C. M.; RIVA, H. C.; RIOS, T. H. C. As expressões idiomáticas de matriz comparativa. São Paulo: UNESP, 1994. 
WELKER, H. A. Dicionários: uma pequena introdução à lexicografia. Brasília: Thesaurus, 2004 .

WELKER, H. A. Panorama Geral da Lexicografia Pedagógica. Brasília: Thesaurus, 2008.

ZAVAGLIA, C.; NADIN, O. L. (orgs). Lexicografia Pedagógica. Revista Domínios de Lingu@gem. Uberlândia, Universidade Federal de Uberlândia, v. 12, n. 4. 2018. 